\title{
TENSOMETRIC CHARACTERISTICS OF DE-EPITHELIZED SKIN GRAFT AND POLYPROPYLENE MESH IMPLANT USED IN HERNIOPLASTY
}

\begin{abstract}
Mikhail Topchiev (D, Dmitry Parshin ${ }^{\bowtie}$ (D), Ahmed Nurmagomedov $(\mathbb{D}$, Andrei Topchiev (1), Ildyrym Mukhtarov (D)
\end{abstract}

Astrakhan SMU of the Ministry of Health of Russia, Astrakhan, Russia

parshin.doc@gmail.com

ABSTRACT - The purpose of the research work was to study the mechanical properties of a de-epithelized skin graft and polypropylene mesh prosthesis used in herniology. Tensometric studies included: tensile strength and bursting strength of suture material. The average value of tensile load of the skin graft is $51,2 \pm 4,1 \mathrm{~N} / \mathrm{cm}^{2}$, of a synthetic implant $19,9 \pm 3,4 \mathrm{~N} / \mathrm{cm}^{2}$. It was noted, however, that the compliance of the skin graft is higher than that of the mesh implant. The average value of the bursting strength of the skin graft by suture material is $20,1 \pm 2,7 \mathrm{~N} / \mathrm{cm}^{2}$. The skin graft, while maintaining anisotropy during tensometric studies, showed the ability of compliance and tensile strength more than 2 times higher, and the bursting strength 1,4 times higher than the polypropylene implant.

KEYWORDS - ventral hernia; mesh implant; autodermal transplant; tensometry.

\section{RELEVANCE}

Restoring the anatomical structures of the anterior abdominal wall with ventral hernias is a common surgical procedure. Over the past twenty years, the standard way of the reconstruction of defects of the anterior abdominal wall is the use of artificial mesh alloprostheses $[1,2,3]$. However, with their use, complications are noted (seroma, hematoma, suppuration, fistula formation, rejection, prosthesis migration, etc.). This encourages researchers to use the biological tissue. The available literature of recent years vigorously reflects studies of the tensometric properties of allografts. However, studies on the mechanical properties of biological implants are highly insufficient. Therefore, the study of the mechanical properties of the biological and synthetic implants is relevant $[4,5]$. The purpose of this research work was to study the mechanical properties of a de-epithelized banked skin graft and polypropylene mesh prosthesis used in hernia surgery.
MATERIALS AND METHODS.

Tensometric tests to study such parameters as tensile strength and bursting strength of suture material were carried out in a certified laboratory for materials study. For this research we used a test laboratory kit with a software for the strength of materials from PASCO AR-8214 (USA). As a polypropylene mesh implant, a prosthesis was used with thread thickness of $0,60-0,68 \mathrm{~mm}$ and a density of $65 \mathrm{~g} / \mathrm{m}^{2}$. A de-epithelized banked human skin flap was used as a bioimplant. Skin samples were taken from patients during operations at the site of excised "old" postoperative scar. Further, the skin flap was prepared according to our own original technology including its deepithelialization with a dermatome, preservation in a special solution containing an antibiotic and an oxygenated preparation in a certain ratio (Patent for the invention No. 2011132679/14, dated 03.08.2011). 10 samples were compared. The width of the samples was $10 \mathrm{~mm}$. The result of the study was shown by a graph of the deformation curve (tensile diagram) in the coordinates: ordinate - tension $(\mathrm{N} / \mathrm{cm} 2)$, abscissa relative elongation (\%). The breaking load $\left(\mathrm{N} / \mathrm{cm}^{2}\right)$ was calculated as a result of multiplying the maximum tension by the thickness of the sample. Statistical analysis of the obtained data was carried out using Data Studio software, STATISTICA 6.0 application software package.

\section{RESULTS}

The mesh and skin flaps of the implants showed linear elongation. Tensometry of both types of samples at the beginning of the study revealed a relatively uniform distribution of the load without resistance. At the same time, it was noted that the compliance of the de-epithelized banked skin graft is 1,5-2 times higher than that of the mesh implant and depends on the thickness of the sample, i.e. it represents a flatter curve than that of a polypropylene implant. The average values of the tensile load under uniaxial stretching of a free de-epithelized banked skin graft at 100\% deformation amounted to $51,2 \pm 4,1 \mathrm{~N} / \mathrm{cm}^{2}$. The average values of the tensile load of a polypropylene mesh implant under uniaxial tension along the base was $19,9 \pm 3,4 \mathrm{~N} / \mathrm{cm}^{2}(\mathrm{p}<0,05)$ (see Fig. 1). The maximum average value of the bursting of the de-epithelized 
Fig. 1. The average values of the tensile load of a de-epithelized autodermal transplant (DEAT) and a polypropylene implant PPI under uniaxial stretching (along the base) $(M \pm m)$

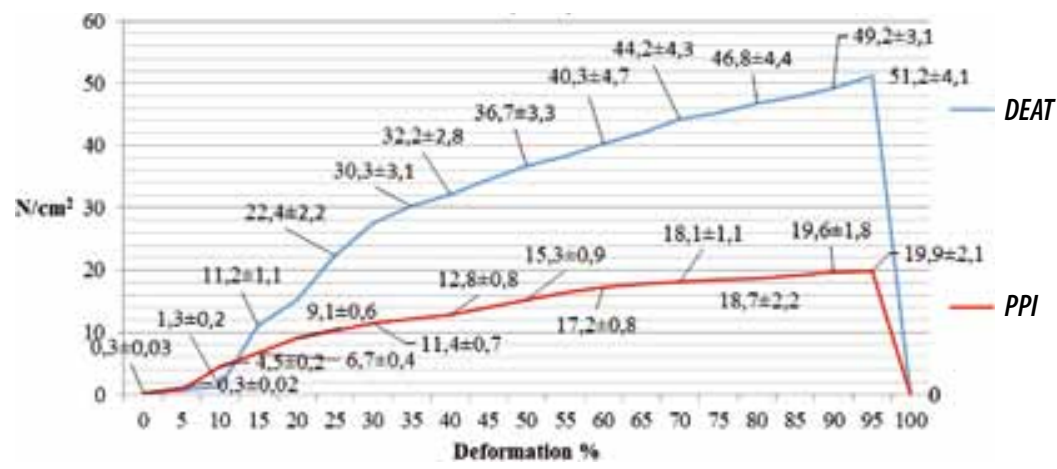

banked skin graft by suture material at its $100 \%$ deformation was $28,1 \pm 3,7$ $\mathrm{N} / \mathrm{cm}^{2}$. At the same time, the maximum average value of the bursting of a polypropylene mesh implant by suture material, with its $100 \%$ deformation was $20,1 \pm 2,7 \mathrm{~N} / \mathrm{cm}^{2}$ ( $\left.\mathrm{p}<0,05\right)$ (see Fig. 2). When studying the mechanical properties of a de-epithelized skin graft and a polypropylene mesh implant, a certain mathematical dependence was revealed expressed by the formulas: for a polypropylene mesh graft $y=2 x$; for a de-epithelized banked free skin graft $y=(3,5 \div 4,0) x$. Where $x$ is the abscissa axis (deformation \%), and $y$ is the ordinate axis (breaking load $\mathrm{N} / \mathrm{cm}^{2}$ ).

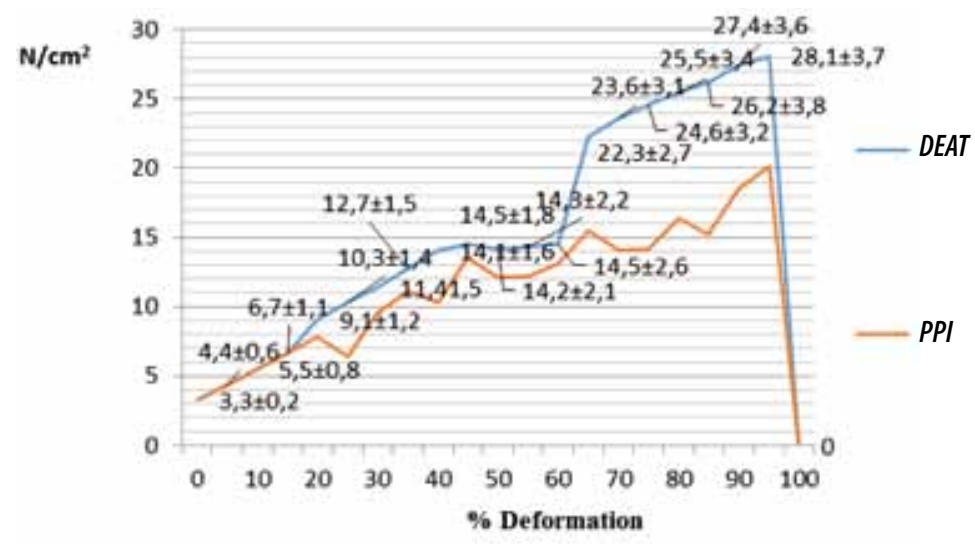

Fig. 2. The average values of the bursting strength of a de-epithelized autodermal transplant (DEAT) and a polypropylene implant PPI by suture material $(M \pm m)$

\section{DISCUSSION}

Studies of the mechanical properties of the skin graft made it possible to acknowledge its greater strength, as expressed in the tensile load parameters, which amounted to $51,2 \pm 4,1 \mathrm{~N} / \mathrm{cm}^{2}$. A similar trend was reflected in the indicators of research on the bursting strength of suture material. The results on the bursting strength test of the suture material were higher than those of the mesh implant and amounted to $28,1 \pm 3,7 \mathrm{~N} / \mathrm{cm}^{2}$. The compli- ance of the de-epithelialized skin graft was 1,5 times higher than that of the mesh implant. At the same time, it should be noted that a skin flap is characterized by flexibility, fluidity, compliance. The bioimplant exhibits this property at high loads of $15 \mathrm{~N} / \mathrm{cm}^{2}$ with its $50 \%$ deformation. This quality was absent in the synthetic mesh prosthesis, where under similar loads the deformation curve had the form of a sinusoid, which is associated with the gradual rupture of the threads of the polypropylene prosthesis. This quality of the skin graft, in our opinion, is valuable and brings it closer to the anisotropic mechanical properties of the anterior abdominal wall.

\section{CONCLUSION}

The results obtained in an experimental test of a skin transplant prepared by the proprietary methodology showed the ability of compliance, fluidity and strength, which is typical for biological tissues that include both collagen and elastin fibers. All this is confirmed in terms of tensile load indicators and indicators of the bursting strength of suture material. The results indicate the eligibility of skin graft in hernia surgery.

\section{REFERENCES}

1. AnNor AH, TANg ME, Pui CL, Ebersole GC, Frisella MM, Matthews BD, DeEken CR. Effect of enzymatic degradation on the mechanical properties of biological scaffold materials. Surg Endosc. 2012;26:2767-2778. DOI: $10.1007 /$ s00464-0122277-5.

2. BINNEBÖSEL M., RosCH R., Junge K., Flanagan T.C., SCHWAB R., SCHUMPELICK V., KLINGE U. Biomechanical analyses of overlap and mesh dislocation in an incisional hernia model in vitro. Surgery. 2007;142(3):365371. DOI:10.1016/ j.surg.2007.04.024. 
3. Lintin L.A., KingSNORTh A.N. Mechanical failure of a lightweight polypropylene mesh. Hernia. 2014;18(1):131-133. DOI:10.1007/s10029-012$0959-5$.

4. V.P. AKimov, D.Y. Krikunov, D.S. Parshin, V.Y. Mikhaylichenko, V.V. Toidze, M.Z. ChURGULIA. Possibilities of using the adhesive method of fixation of the mesh implant in laparoscopic treatment of inguinal hernias. Taurian Medical and Biological Bulletin. 2018;21(1):7-14. Available on: https:// elibrary.ru/download/elibrary_35297386_91810738. pdf.
5. V.A. Samartsev, V.E. Wildeman, S.V. SLOvikov, V.A. Gavrilov, A.A. Parshakov, M.P. KuZNETSOva, A.Y. Sidorenko. Assessment of the biomechanical properties of modern surgical mesh implants: an experimental study. Russian Journal of Biomechanics. 2017;21(4):442-448. DOI: 10.15593/ RZhBiomeh/2017.4.11. 